\title{
PLANEJAMENTO, GESTÃO E EXECUÇÃO DE PROJETOS: UMA ARENA DE CONFLITOS ENTRE REDES DE ATORES
}

Cristiano Desconsi*

\begin{abstract}
Resumo
Esse artigo pretende refletir sobre a relação entre as estratégias de organização dos atores em redes e as disputas em torno do planejamento, da gestão e da execução de projetos que evidenciam conflitos no âmbito territorial. Utilizando como base a análise teórica e o exame da bibliografia especializada, o texto expõe algumas discussões teóricas acerca da noção de redes, para, em seguida, chamar a atenção para a importância de compreender os conflitos que surgem em torno do planejamento, da gestão e da execução de projetos, dando ênfase à organização dos atores em redes nas disputas, aos conflitos socioambientais associados à implantação de "grandes projetos" e, por fim, às tensões entre projetos entre os próprios atores locais que se expressam em espaços de participação instituídos para gerir algumas modalidades de projetos territoriais. A partir desse percurso argumentativo, sugere-se que os conflitos são constitutivos do processo de planejamento, gestão e execução de projetos. Não raramente, os atores não apenas se organizam em redes estabelecendo alianças com outros atores para planejar, gerir e executar projetos segundo suas concepções, como também o fazem para lutar contra, impedir, barrar, modificar projetos que são impostos por redes de outros atores sobre seus territórios e modos de vida.
\end{abstract}

Palavras-chave: Projetos. Redes. Atores. Conflitos. Território.

\footnotetext{
* Sociólogo, Doutor em Ciências Humanas (Antropologia Cultural) pelo Programa de Pós-graduação em Sociologia e Antropologia da Universidade Federal do Rio de Janeiro (PPGSA/UFRJ) e Pós-doutorando em Agroecossistemas pela Universidade Federal de Santa Catarina (PGA/UFSC). E-mail: crdesconsi@gmail.com
} 


\section{Introdução}

As discussões em torno do planejamento, da gestão e da execução de projetos sempre são acompanhadas pela sua interface com os atores sociais envolvidos em todo o processo. Isso porque os projetos são instrumentos de ação e de mobilização dos atores que permitem materializar o alcance de determinados objetivos ou resultados. No âmbito dos territórios, a imbricação entre os projetos e redes de atores coloca em evidência os conflitos, os quais podem ser observados a partir das disputas, dos interesses, e das estratégicas ou alianças que são articuladas e organizadas para fazer valer suas visões de mundo, perspectivas de desenvolvimento ou posição social (DIAS, 2005).

Ainda que a efetivação de um determinado projeto (de infraestrutura, de desenvolvimento rural, social, de estruturação ou fortalecimento de sistemas produtivos, de combate à pobreza, de formação, entre outros) integre ou produza controvérsias e disputas entre os vários atores no âmbito territorial, raramente essa disputa se efetiva apenas em uma única escala. As transformações associadas ao processo de globalização nas últimas décadas recolocam a relação entre as escala global e local, por meio do aumento dos fluxos de informações, da circulação de materiais, do capital e das formas de interação dos diversos atores (DIAS, 2005). A complexidade das interações se manifesta nos e para além dos territórios e fazem com que os atores (desde pequenas e médias empresas, transnacionais, movimentos sociais, ONGs, agricultores, órgãos do Estado, pesquisadores etc.) desenvolvam novas formas de organização e de estratégias de ação. Dito de outra maneira, os atores buscam novas formas de articulação entre o local e o global, estabelecendo alianças e estratégias variadas e flexíveis, em interconexões que se configuram como novas formas de organização. É nesse contexto que a noção de rede passa a ser um recurso acionado pelos atores diversos em seus sentidos metafórico, analítico ou informacional para fazer frente ao novo contexto (ACIOLI, 2007; DIAS, 2005), sendo incorporada ao vocabulário dos profissionais e pesquisadores que atuam com planejamento, gestão e execução de projetos.

Situado nessa temática, esse texto pretende colocar em evidência a relação entre as estratégias de organização dos atores em redes e as disputas envolvendo planejamento, gestão e execução de projetos que evidenciam conflitos no âmbito territorial. Para tratar desse objeto, o texto está dividido em três seções: a primeira expõe algumas discussões teóricas acerca da noção de redes, para, em seguida, dar ênfase às novas formas de organização dos atores em rede, bem como seus objetivos, capacidade e recursos. As duas seções seguintes procuram refletir sobre os conflitos em torno do planejamento, da gestão e da execução de projetos, 
dando ênfase à organização dos atores em redes nas disputas. Para fins da exposição, a segunda seção destaca os conflitos socioambientais associados à implantação de "grandes projetos" e/ou empreendimentos empresariais e sua localização no território, os quais geralmente são planejados e geridos para além da escala onde serão executados. A última seção trata das disputas entre projetos entre os próprios atores locais, visto que estes também constituem redes e estratégias de mobilização em múltiplas escalas para viabilizar a implementação de um projeto ou, ainda, contrapor-se a projetos protagonizados por outros atores locais. Os espaços de participação - como conselhos fóruns, colegiados, audiências públicas consultas - são apenas uma das múltiplas arenas onde se constatam disputas em torno de projetos.

\section{Redes de atores no e para além do território}

As noções de rede vêm sendo muito utilizadas na teoria e prática de várias áreas do conhecimento (geografia, sociologia, antropologia, administração, engenharias, economia, demografia etc.), além de serem mobilizadas para tratar dos mais variados objetos. Sem a preocupação de estabelecer uma noção precisa, cabe fazer algumas observações quanto às abordagens associadas à noção de redes, de modo a permitir uma reflexão entre as redes e os conflitos relacionados ao planejamento, à gestão e à execução de projetos de desenvolvimento.

Acioli (2007) e Scherer-Warren (2015) observam que as abordagens de redes permitem três tipos de uso: metafórico, analítico e tecnológico. Nas abordagens metafóricas, aparece uma filosofia da rede, ou seja, procurase compreender a construção e ativação de laços sociais entre indivíduos e grupos que configuram formas de organização, não necessariamente estruturadas ou institucionalizadas. Nessa direção, muitas vezes os atores assumem o próprio termo rede para caracterizar suas estratégias de mobilização. Citam a abordagem analítica, por meio da qual é acionada uma série de metodologias para análise de rede. Por fim, mencionam a abordagem tecnológica, cujo foco está nas redes de conexões, fluxos e intenções, possibilidades que se colocam em relação às interações possíveis da sociedade por meio das redes eletrônicas, de informações, temáticas, interorganizacionais etc.

$\mathrm{O}$ uso da noção em termos analítico e metafórico não é novo. $\mathrm{Na}$ antropologia britânica, foi onde apareceram os primeiros trabalhos que acionam a noção de rede visando a enfrentar os problemas do estruturalfuncionalismo e da compreensão das mudanças sociais. Elizabet Bott analisou as redes sociais das famílias inglesas, isto é, os elos sociais dentro de uma unidade básica de estudo. Outros antropólogos ligados ao grupo de M. Gluckmann (Kapferer, Barnes, Mayer, entre outros), de forma geral, 
usaram a noção de rede para estabelecer os elos de um grupo (ou conjunto deles) e os indivíduos nele contidos, em relação aos grupos e indivíduos definidos como externos a essa unidade. As discussões giram em torno do conteúdo e da forma das redes, de seus pontos de ancoramento (indivíduo ou coletividade), conteúdo e densidade (MITCHELL, 1969).

Essas abordagens aprimoradas pela antropologia e sociologia vêm sendo atualizadas em pesquisas recentes relacionadas aos processos de desenvolvimento em contextos específicos. Para ilustrar, é relevante citar duas pesquisas recentes. A primeira é de Desconsi (2017), a qual trata da produção de soja entre assentados rurais do Mato Grosso. O autor faz uso da análise de rede associada aos modos de dominação para evidenciar controle das lavouras de soja, a partir do exame dos acordos e das trocas entre os assentados e destes com outros atores (produtores e empresas), não restritos a uma unidade territorial delimitada. A segunda pesquisa é de Radowski (2006), a qual faz uso dessa noção para examinar as redes de reciprocidade - de trabalho e sociabilidade - que estruturam as relações entre os atores sociais, constituindo-se como uma forma de regular os mercados, a concorrência e os conflitos entre atores locais na serra gaúcha. Nesses dois estudos, com perspectivas distintas, dentre tantos que poderiam ser citados nas ciências sociais, há a possibilidade de tratar de redes de atores e conflitos para examinar as especificidades do desenvolvimento de determinadas regiões ou territórios.

Conforme Acioli (2007), o uso tecnológico (redes sociais) certamente é o mais utilizado atualmente, embora ele não esteja descolado das abordagens metafóricas e analítica. Castells (1999) aponta para a emergência do paradigma da informação, da sociedade em rede, algo que somente é possível pelas novas tecnologias da informação, visto que permitem criar: i) novas espacialidades, com relações sociais mediadas por computadores, de modo que os conflitos reverberam nas redes telemáticas para o cotidiano das pessoas e vice-versa; ii) novas temporalidades, por possibilitarem a comunicação em tempo real de qualquer lugar do mundo, mesclando diálogos em tempos distintos; iii) novas formas de sociabilidade estabelecendo novos vínculos, conformação da esfera pública e privada e constituição identitária de indivíduos e grupos, as chamadas redes sociais. Em suma, Castells (1999) considera que uma estrutura social baseada em rede é um sistema aberto, dinâmico e suscetível de inovação. Nesses termos, as redes se caracterizam pela fluidez (organizacional), por terem uma finalidade, capacidade de alcançar resultados e de gerar aprendizagem.

Scherer-Warren (2015) utiliza a abordagem das redes para tratar das novas modalidades de organização das ações coletivas, As "redes de movimentos" ou os "movimentos organizados em rede" permitem estabelecer estratégias de articulação entre o local e o global, entre o 
particular e o universal, entre o uno e o diverso, nas interconexões entre os atores em sua pluralidade. A discussão da autora, preocupada com as novas formas de ação coletiva, encaixa-se nas preocupações de outros autores que vão tentar observar as novas formas de organização ou mesmo da divisão social e espacial do trabalho na era da globalização, que evidencia a análise das noções de rede associada ao aumento e às novas formas de interação possíveis pelas tecnologias de informação.

É certo que os usos metafóricos, analítico e tecnológico se entrecruzam e interpõem. Mas o que se pode afirmar a partir da literatura é que as abordagens de redes privilegiam a análise dos fenômenos a partir das relações sociais e não a partir dos atributos dos atores (ACIOLI, 2007; DIAS, 206; SCHERER-WARREN, 2015). As abordagens valorizam as estratégias dos atores, a flexibilidade das interações entre eles para, a partir disso, pensar a configuração de relações sociais concretas em distintas temporalidades e espaços (DESCONSI, 2017). É a partir dessa perspectiva que as "abordagens de redes" são postas em relação às diversas articulações entre indivíduos e grupos em rede configuradas no território (DIAS, 2006, SANTOS, 2009).

E, a partir dessa literatura, as redes configuram-se como redes de movimentos sociais, atores da sociedade civil que se mobilizam para mediar estratégias na esfera pública (SCHERER-WARREN, 2015), redes interorganizacionais de empresas como forma de constituir vantagens competitivas e especificidades no mercado (BALESTRIN; VARGAS, 2002), redes horizontais de empreendimentos da agricultura familiar para gerir e comercializar produtos em circuitos curtos em contraponto com as redes verticais das grandes cadeias agroindustriais (MIOR, 2005), redes de cooperação de pequenas empresas para ampliar a capacidade de atuação territorial (ALMEIDA; SIVEIRA, 2015), entre outras.

As várias formas (virtuais, sociais, temáticas) supõem indivíduos, grupos ou organizações que se articulam, ainda que temporariamente, visando a alguns objetivos confluentes, permitindo estabelecer interações entre si que ampliem suas capacidades e seus recursos disponíveis, para fazer frente a determinados desafios ou adentrar com maior força nas arenas em disputa onde estão inseridos. É essa a definição de rede assumida para fins da reflexão contida nesse texto, ou seja, assume-se a noção de redes como uma forma de organização flexível construída pelos atores para determinados fins específicos, como estabelecer disputas envolvendo planejamento, gestão e execução de um projeto ou, ainda, viabilizar determinado projeto e não outro.

Para fins de exposição, nas seções seguintes distinguem-se os conflitos em torno dos projetos em duas grandes modalidades. O primeiro referente aos "grandes projetos" e/ou empreendimentos que são ou serão localizados nos territórios. Essa modalidade caracteriza-se pelo planejamento e pela 
gestão, ocorrendo em centros decisórios localizados em outras escalas e contatando com atores que raramente têm contato com o próprio local onde o projeto está previsto. Logo, é a execução o ponto de maiores controvérsias e conflitos, tendo em vista que concretiza no território uma série de mudanças nas relações sociais e na paisagem. O segundo se referem aos conflitos em torno de projetos, que são planejados, geridos com maior protagonismo dos atores locais. Estabelecem-se disputas em torno de distintos projetos (desde sua concepção, planejamento, gestão e execução), pois o êxito ou fracasso deles colabora para manter ou alterar as relações de poder entre os atores.

\section{Os embates relativos aos "grandes projetos" e sua localização no território}

A literatura das várias áreas do conhecimento (sociologia, antropologia, economia, administração e geografia) chama atenção para as transformações decorrentes da globalização, cujo processo, em seu sentido mais amplo, tende à padronização e homogeneização do modelo predominante de desenvolvimento. Nesse processo, os autores constatam que o território (escala local e regional) é onde se materializam os conflitos sociais que, ainda que inscritos ali, nem do ponto de vista da análise, nem da efetivação das tensões entre os atores se resume a essa localidade (BACELAR, 2009). Nesse sentido, é fato que, nos últimos anos, crescem as discussões sobre os grandes projetos ou empreendimentos e seus efeitos sobre o âmbito local. Muitos desses grandes projetos ou empreendimentos (usinas hidrelétricas, parques eólicos, estradas, agriculturas empresariais, parques industriais, resorts a beira mar, complexos de mineração, entre outros) são expressões das estratégias de territorialização de grandes empresas, corporações transnacionais viabilizadas com apoio estatal (BÜHLER; GUIBERT; OLIVEIRA, 2016). Talvez, uma das marcas dos "grandes projetos" definidos como estratégicos por corporações ou governos é seu caráter arbitrário sobre os atores onde este será localizado. Trata-se do dilema da participação que raramente é um aspecto que se faz presente efetivamente no planejamento, na gestão e na execução desses projetos definidos pelos governos e empreendedores como estratégicos para o país. A participação se resume a fóruns, audiências públicas, consultas aos atores afetados; porém, não está em questão a não realização do projeto, quando muito se tratam de espaços de discussão sobre compensações do projeto ou mesmo espaços onde atores ligados aos governos e empreendedores tentam convencer a população local dos benefícios do projeto (LEITE LOPES, 2006).

Nesse sentido, o planejamento, a gestão são competências de atores distantes dos atores locais (por vezes, desconhecidos), além de serem 
modulados por profissionais especializados em escritórios e gabinetes, não raro, situados em grandes metrópoles ou até em outros países (BÜHLER; GUIBERT; OLIVEIRA, 2016). Então, por um lado, o controle das informações sobre o projeto não é só objeto de disputa mas também integra as disputas pelas narrativas sobre o próprio projeto (características, expectativas, benefícios e malefícios); por outro lado, o distanciamento dos atores locais do planejamento e da gestão do projeto salienta o momento da sua execução como o de maior acirramento dos conflitos, pois é quando o projeto se concretiza. O ponto em questão é que os atores locais precisam construir mobilizações a fim de estabelecer alianças variadas com outros afins e operar em estratégias em múltiplas escalas, se seu objetivo é barrar, ajustar, reformular os "grandes projetos", conformando uma arena de disputa dispersa em vários lugares e tempos. Efetivam, dessa maneira, estratégias similares aos responsáveis ou "favoráveis" aos "grandes projetos" e termos de operações que envolvem empresas, governos, prefeituras, bancos, mídia, associações civis, órgãos do judiciário, entre outros.

Os conflitos socioambientais que surgiram nas últimas décadas são os que melhor exprimem esses pontos de tensão entre grandes empreendimentos e sua localização dos territórios e os impactos diante dos muitos grupos sociais que ali vivem. Leite Lopes (2006) destaca a ambientalização dos conflitos sociais, ou seja, os aspectos ambientais degradação do solo, uso de agrotóxicos, poluição industrial, alteração da paisagem, barramento do curso de rios, entre outros - que afetam a vida de grupos sociais dominados e assumem posição central nos conflitos com os grupos dominantes. Não por acaso, as narrativas dos atores contrários à instalação de grandes projetos e empreendimentos sempre enfatiza os efeitos negativos causados nas comunidades locais e no ecossistema.

Nessa direção, Fleury e Almeida (2013) analisam o conflito decorrente da usina hidrelétrica de Belo Monte. O estudo coloca em evidência disputas e controvérsias envolvendo atores diversos que perpassam o planejamento, a gestão e a execução do projeto em múltiplas escalas. Os atores contrários ao projeto, especialmente movimentos sociais e ONGs ambientalistas constituíram uma organização em rede, chamada de Movimento Xingú Vivo, a partir da qual se estabeleciam alianças diversas e enfrentamentos desde o canteiro de obras, em escritórios em Brasília, no congresso nacional, em instâncias judiciais, em redes sociais da internet, em conferências internacionais, em audiências públicas e espaços da academia, entre outros. Em cada um desses momentos, pareceres técnicos, cartas, estudos, listas, documentários, protestos, destruição de parte das obras, constituíram-se instrumentos utilizados para fazer frente à obra. As alianças e estratégias também se modificam em cada etapa do projeto, sendo expressas em lutas simbólicas e materiais as quais têm como pano de fundo, visões distintas 
sobre o próprio estilo de desenvolvimento que é mais adequado para aquele território. Fleury e Almeida (2013) enfatizam que há uma espécie de roteiro mais ou menos comum que acompanha o processo de planejamento, gestão e execução desses grandes empreendimentos, aspecto que pode ser verificado nas inúmeras pesquisas que estão se dedicando a analisar os impactos socioambientais de grandes empreendimentos situados, de alguma maneira, em quase todas as áreas do Brasil.

Essa e outras pesquisas sobre o tema dos conflitos envolvendo projetos e empreendimentos permitem afirmar que os "grandes projetos" ou empreendimentos empresariais não podem ser compreendidos como "forças" externas que entram em confronto com os atores do território, em uma oposição perfeita entre atores externos e locais. Os estudos demonstram que os atores responsáveis por grandes projetos e/ou empreendimentos dialogam com os gestores locais ou participam das articulações entre produtores rurais, técnicos, prefeitos, empresários e movimentos sociais. Segundo Leite Lopes (2006), isso está relacionado à necessidade de os empreendedores e responsáveis pelos projetos de se apropriarem das críticas, amenizarem suas operações, proporem e realizarem projetos compensatórios associados de modo a fazer avançar em seus objetivos. Assim, geralmente, os empreendedores fazem valer seus "grandes projetos" a partir "de fora", e estes somente se concretizam. Os empreendedores são capazes de angariar apoiadores, parceiros e redes na escala local, como também se fortalecem por meio do estabelecimento ou da constituição de novos atores sociais associados à execução do próprio projeto. São estes novos atores (engenheiros, responsáveis pelas obras, empresários associados, pesquisadores, entre outros) que passam a atuar no território, muitas vezes sendo os responsáveis por travar e garantir as condições para a implementação dos empreendimentos ou "grandes projetos" (sobretudo na fase de execução), mesmo que a modulação tenha ocorrido muito distante dali. De diferentes maneiras, isso foi analisado em estudos que tomaram contextos locais específicos, tais como: a instalação e operação de empresas de papel e celulose e as monoculturas de eucalipto no sul do Rio Grande do Sul (BINKOWSKI, 2014), na expansão da produção de soja entre assentados do norte do Mato Grosso (DESCONSI, 2017); em territórios onde predomina a produção de cana-de-açúcar (REYDON; MARQUES POSTAL, 2016); nos impactos do projeto Complexo Petroquímico do Rio de Janeiro (COMPERJ) sobre as populações do entorno (OLIVEIRA; BÜHLER, 2015), entre outras pesquisas que poderiam ser citadas.

Nesses termos, a literatura sobre conflitos socioambientais em torno de grandes projetos coloca em evidência que o conflito não se resume aos defensores e contrários aos projetos ou empreendimentos, havendo 
contradições, limitações internas aos próprios atores, assim como reações, recuperações e restaurações de práticas e alianças (LEITE LOPES, 2006).

\section{Atores no planejamento, gestão de projetos de desenvolvimento}

Vimos, na seção anterior, que os grandes projetos e empreendimentos que envolvem grandes multinacionais e corporações têm como característica o pouco protagonismo dos atores locais, sobretudo no planejamento e gestão. Contudo, há um conjunto de situações em que alguns atores locais assumem o protagonismo na construção de projetos, assumindo o planejamento, gestão e até a execução. Nesses casos, constroem redes para além do território ou da escala local, de modo a angariar forças e capacidades para concretizar a implementação dos projetos. $\mathrm{O}$ fato de um projeto ser planejado, ou até gerido e executado por atores locais não o exime ou minimiza a existência de conflitos, tendo em vista que os territórios não são constituídos pela heterogeneidade de atores e respectivos interesses, percepções sobre o desenvolvimento e posições sociais (DESCONSI, 2017).

Nas últimas décadas, diversos movimentos sociais e organizações da sociedade civil com o apoio de organizações internacionais, por vezes, de órgão do Estado ou mesmo de pesquisadores das universidades, construíram redes de atores articulando em torno de temáticas específicas - agroindústrias familiares, agroecologia, economia solidária, arranjos produtivos locais, justiça ambiental - informados sobre novas perspectivas de desenvolvimento. Entre as ações, não estava somente a luta contra atores sociais dominantes associados aos empreendimentos e a concepções predominantes de desenvolvimento mas também a construção ações práticas para concretizar experiências de organização, produção, consumo, participação na escala local. Nesse sentido, por meio dessas redes de atores, foram planejados, geridos e executados vários projetos "alternativos". Um projeto, nesse sentido, trata-se de um instrumento operacional que organizar ações e aglutinar os recursos necessários visando a alcançar resultados e mudanças; entretanto, também se torna um instrumento de mobilização social de uma rede de atores seja no planejamento, na gestão e na execução. Nesses termos, os projetos materializam percepções cosmopolíticas de desenvolvimento, porque, em qualquer região, é fácil encontrar projetos em disputa.

Mior (2005) observou a construção de redes horizontais entre atores para conformação de projetos de agroindústrias familiares em circuitos locais no Oeste Catarinense. Os projetos de implementação de agroindústrias visavam a construir um sistema produtivo que se distinguia das redes verticais das agroindústrias do setor de aves e suínos, hegemônicas na região e envolvia redes de atores locais (agricultores, familiares, sindicatos, associações, movimentos sociais, universidades, algumas prefeituras). Logo, 
o autor demonstra que se constituíram vários pontos de encontro entre essas duas perspectivas na escala local, por meio de projetos específicos que envolviam parcerias entre as grandes agroindústrias com as familiares para produzir produtos diferenciados, assim como projetos de agroindústrias familiares que acabaram assumindo o sistema produtivo e organizacional similar ao das grandes agroindústrias.

A chamada guerra fiscal que marcou a década de 1990 e 2000, ou seja, a disputa entre estados, municípios e regiões pela localização de projeto, por meio de incentivos diversos, muitas vezes ocorreu em paralelo com as iniciativas de cooperação entre os atores locais e regionais no sentido de fortalecer especificidades. Em experiências que acompanhei no noroeste do Rio Grande do Sul, os prefeitos, as universidades e outras lideranças regionais haviam desenvolvido projetos interessantes na área da agroindustrialização do leite (pequenas cooperativas e redes de agroindústrias familiares) e de geração de energias renováveis, potencializando recursos e empresas locais. Contudo,esses mesmos agentes, atuavam com articulações em escala nacional e internacional para atrair grandes projetos de construção de barragens e multinacionais do setor de laticínios. O primeiro não se realizou até hoje; mas, o segundo, ao ser efetivado pela instalação de grandes empresas - cujo planejamento foi realizado no âmbito local por alguns atores - retirou todos os recursos destinados aos projetos de agroindústrias familiares e das cooperativas e inviabilizou a existência destas na maioria dos casos. São conflitos entre concepções sobre o desenvolvimento expressos em projetos, que nem sempre são possíveis de coexistência no âmbito de um mesmo território. $\mathrm{Na}$ medida em que alguns desses projetos ganham possibilidade de sucesso, isso influencia diretamente o fortalecimento ou não de alguns atores locais. Nesses termos, o êxito ou fracasso de determinados projetos é um elemento central nas produção/manutenção das relações de poder no âmbito territorial. Essa é possível; afinal, no plano local ou regional, ainda que sejam valorizados os elementos endógenos, é comum o desenvolvimento de projetos e iniciativas que pretendem "atrair investimentos" ou "projetos" e externos, sobretudo de grandes empresas.

Cabe destacar que, a partir das décadas de 1980 e 1990 - quando a participação e a cidadania tornam-se bandeiras importantes dos movimentos sociais e da sociedade civil -, foram instituídos vários espaços, como conselhos, fóruns, audiências públicas, colegiados e consultas, visando a ampliar a interlocução entre o Estado e a sociedade, especialmente quanto à gestão e ao planejamento de políticas, programas e projetos. Os conflitos decorrentes de redes de atores, também se fazem presentes nesses espaços. Observar alguns aspectos sobre as experiências bem conhecidas dos Conselhos Regionais de Desenvolvimento (COREDES) (1991 e ainda vigente) e do Programa Nacional de Territórios Rurais (PRONAT) 
e Programa Territórios da Cidadania ${ }^{1}$ (PTC) (2004 a 2015), a partir de alguns estudos, é suficiente para colocar em evidência a manifestação de conflitos.

Silveira et al. (2015) examina os limites e as potencialidades da participação no planejamento estratégico dos COREDES. Dentre suas constatações, observou que inúmeros projetos definidos como estratégicos nos planejamentos regionais não são efetivados pelos órgãos de estado responsáveis, o que provoca certo esvaziamento dos conselhos. Isso é o caso, em particular, de projetos de infraestrutura (asfaltamento, melhoria e duplicação de rodovias, por exemplo). É provável que isso esteja associado à constatação de que a maioria dos COREDES tem pouca participação do setor privado (como empresários locais dos vários setores econômicos). Estes planejam projetos "para a região" (especialmente de infraestrutura); contudo, mobilizam redes que alcançam bancos, governos estadual e federal, prefeitos, empreiteiras, associações empresarias, mídia entre outros, passando "por fora" dos COREDES. Por fim, o autor observou a força de atores da área de saúde, da educação ou segurança que fazem com que os projetos estratégicos sejam também temáticos, não atendendo diversas dimensões do desenvolvimento.

Algumas análises sobre o PRONAT e PTC, em especial sobre o planejamento de projetos constatam experiências similares. $\mathrm{Na}$ construção dos planos de desenvolvimento territoriais, alguns atores com maior capacidade de articulação fazem prevalecer seus projetos, por vezes negligenciando outros atores existentes no território. Segundo Grisa (2013), em muitos casos, organizações de agricultores familiares fizeram prevalecer projetos produtivos que fortaleciam determinadas cadeias produtivas já existentes, e projetos associados aos assentados, indígenas, quilombolas ficaram fora dos projetos prioritários. A autora também constatou que maioria dos projetos deliberados tem um caráter setorial e não contempla ou não considera a perspectiva multidimensional no âmbito do território.

Observa-se, assim, que os projetos de desenvolvimento regionais e territoriais são assumidos por alguns atores, raramente sendo assumidos pelo conjunto dos atores locais. Os espaços de participação, como os dois exemplos citados, são apenas mais um espaço que integra a disputa entre os atores e permitem fazer prevalecer seus projetos como parte de um planejamento estratégico regional e territorial. Participar ou não desses espaços, assim como disputar ideias e concepções no planejamento de projetos, depende da avaliação que os atores fazem de suas possibilidades nesses espaços. Muitas vezes não há conflitos evidentes em conselhos, fóruns, tais como os COREDES ou Colegiados Territoriais, porque as principais tensões e questões em jogo entre os atores não passam por essa instância.
1 Tomando como base a abordagem territorial, também foi construída a experiência dos Territórios Rurais e Territórios da Cidadania. Tais programas constituíram os territórios como unidades de planejamento, gestão e execução de políticas, especialmente com o foco do combate à pobreza. Nessa experiência, também se constitui um misto entre processo decisório relativo a algumas políticas públicas, assim como a construção de um planejamento territorial pelos colegiados territoriais, do qual derivam os projetos estratégicos para o território (GRISA, 2013). 


\section{À guisa de conclusão}

A argumentação desse texto sugere que os conflitos são constitutivos do processo de planejamento, gestão e execução de projetos. Não raramente, os atores além de se organizarem em redes - estabelecendo alianças com outros atores para planejar, gerir e executar projetos segundo suas concepções - também o fazem para lutar contra, impedir, barrar e modificar projetos que são impostos por redes de outros atores sobre seus territórios e modos de vida. Nesse sentido, concordamos com Fleury e Almeida (2013) que destacam que, por trás dos conflitos inerentes aos "grandes projetos", estão disputas e controvérsias associadas à própria noção de desenvolvimento, ou seja, às dimensões que são valorizadas nas relações sociais e entre a sociedade e natureza.

Os conflitos entre atores não consistem em uma característica presente somente nos "grandes projetos" ou empreendimentos geridos por corporações empresariais, pois também aparecem em projetos protagonizados por atores locais. Com frequência, o conflito se torna parte constituinte do próprio território, quando entram em cena redes de atores específicas que se organizam ou se mobilizam entorno de determinados projetos a fim de disputar espaços e processos de desenvolvimento em relação a outras redes de atores. Nesses casos, nem sempre a coexistência entre distintos projetos em um mesmo território é possível; afinal, o êxito de um projeto pode comprometer o avanço do outro. Raramente, por mais que seja objeto de discussão em espaços de participação, um projeto contempla os interesses de todos os atores de uma região ou um território. Os exemplos dos COREDES e dos PTC mencionados nesse texto colocam em evidência as disputas por projetos estratégicos que tanto atores fazem prevalecer via esses espaços de participação, projetos que, além de não contemplarem os grupos sociais que possuem menor força política no âmbito local, não representam as reais disputas entre distintos projetos que, em tantos casos, são viabilizados por articulações de alguns atores locais que mobilizam redes em múltiplas escalas.

Em uma realidade marcada por disputas não inscritas somente em uma escala específica, envolvendo múltiplas e dinâmicas interações entre os diversos atores que se movimentam e se reagrupam em ações coletivas, em formas de organização é que as abordagens de redes parecem ganhar relevância. Primeiramente, como um recurso analítico para mapear a complexidade da construção de laços sociais e interações entre os atores; em segundo lugar, pelos próprios atores sociais (como os movimentos sociais e as ONGs) que assumem a própria noção de rede para definirem novas formas de articulação e de desencadeamento de ações coletivas. As disputas em torno de planejamento, gestão e execução de projetos configuram-se 
como arenas específicas, e estas - embora produzam redes específicas para viabilizá-los ou contrariá-los - se interpõem e entrecruzam com outras redes e movimentos outros organizados em torno de outras temáticas e experiências dos atores.

\section{Referências}

ACIOLI, Sonia. Redes sociais e teoria social: revendo os fundamentos do conceito. Informação \& Informação, Londrina, vol. 12, n. 1 esp., p. 8-19, 2007. Disponível em: <http://www.uel.br/revistas/uel/index.php/informacao/article/ view/1784/1520>. Acesso em: 4 nov. 2017

ALMEIDA, Giovana Goretti Feijó de; SILVEIRA, Rogério Leandro Lima da. Redes de cooperação e território: o caso da Associação Rede Casanova. Desenvolvimento em Questão, Ijuí, ano 13, v. 29, p. 158-190, jun./dez. 2015.

BACELAR, 2009. BACELAR, Tânia. Gestão social e desenvolvimento sustentável dos territórios, o desafio da multidimensionalidade: uma visão a partir do Brasil. In: BACELAR, Tânia et al. Gestão Social dos Territórios. Série DRS, IICA, Brasília, p. 35-51, 2009.

BALESTRIN; VARGAS, 2002 BALESTRIN, Alsones; VARGAS, Lilia. Maria. Evidências teóricas para a compreensão das redes interorganizacionais. In: ENCONTRO DE ESTUDOS ORGANIZACIONAIS, 2, 2002, Recife. Anais... Recife: PROPAD/UFPE/ANPAD, 2002. Disponível em: < http://www. anpad.org.br/admin/pdf/eneo2002-46.pdf>, Acesso em 20 mar 18.

BINKOWSKI, Patrícia. Dinâmicas territoriais e disputas territoriais em torno de empreendimentos florestais no sul do RS. 2014. 266 f. Tese (Doutorado em Desenvolvimento Rural) - Programa de Pós-Graduação em Desenvolvimento Rural, Universidade Federal do Rio Grande do Sul, Porto Alegre, 2014.

BÜHLER, Eve Anne; GUIBERT, Martine; OLIVEIRA, Valter Lúcio de. (Org.). Globalização e agriculturas empresarias na América Latina. In:

Agriculturas empresariais e espaços rurais na globalização. Porto Alegre: Editora UFRGS, 2016. p. 7-20.

CASTELLS, Manuel. A sociedade em rede. São Paulo: Paz e Terra, 1999.

DESCONSI, Cristiano. O controle da lavoura: a construção de relações sociais e a produção de soja entre assentados do meio norte de Mato Grosso. 2017. 329 f. Tese (Doutorado em Ciências Humana (Antropologia Cultural) - Programa de Pós-Graduação em Sociologia e Antropologia, Universidade Federal do Rio de Janeiro, Rio de Janeiro, 2017.

DIAS, Leila Christina. Os sentidos das redes. In. ; SILVEIRA, Rogério Leandro Lima (Org.). Redes, sociedades e território. Santa Cruz do Sul: EdUNISC, 2005. p. 11-28.

FLEURY, Lorena Cândido; ALMEIDA, Jalcione. A construção da Usina Hidrelétrica de Belo Monte: conflito ambiental e o dilema do desenvolvimento. Ambiente \& Sociedade, São Paulo, v. 16, n. 4, p. 141-156, 2013. Disponível em: <http://dx.doi.org/10.1590/S1414-753X2013000400009>. Acesso em: 12 nov. 2017. 
GRISA, Cátia. Projetos Estratégicos e ações para o Desenvolvimento Territorial: Uma Análise Do PRONAT e do Programa Territórios da Cidadania. In: MIRANDA, Carlos; TIBÚRCIO, Breno. Políticas de desenvolvimento territorial e enfrentamento da pobreza rural no Brasil. Brasília: IICA, 2013. p. 149-176. (Série DRS).

LEITE LOPES, José Sérgio. Sobre o processo de ambientalização dos conflitos e os dilemas da participação. Horizontes Antropológicos, Porto Alegre, v. 25, n. 12, p. 31-64, 2006. Disponível em: <http://dx.doi.org/10.1590/S0104$71832006000100003>$. Acesso em: 12 nov. 2017.

MIOR, Luiz Carlos. Agricultores Familiares, Agroindústrias e Redes de Desenvolvimento Rural. 1. ed. Chapecó: Editora Argos, 2005.

MITCHELL, J. Clyde. The concept and use of social networks. In: (Ed.). Social Networks in Urban Situations: Analyses of Personal Relationships in Central African Towns. Manchester: Manchester University Press, 1969.

OLIVEIRA, Valter Lúcio de; BÜHLER, Eve Anne. Especulação, exclusão e conflitos: os efeitos dos grandes empreendimentos sobre o rural e os discursos ambientais. In: ENCONTRO DA ANPOCS, 39., 2015, Caxambú. Anais... Caxambú: ANPOCS, 2015.

RADOWSKY, Guilherme Francisco Waterloo. Redes sociais de reciprocidade e trabalho as bases histórico-sociais do desenvolvimento da serra gaúcha. 2017. 207 f. Tese (Doutorado em Desenvolvimento Rural) - Programa de PósGraduação em Desenvolvimento Rural, Universidade Federal do Rio Grande do Sul, Porto Alegre,, Porto Alegre, 2006.

REYDON, Bastiaan Reydon; MARQUES POSTAL, Andreia. Agronegócio sucroenergético: acesso a terra ou acesso à cana? Os diferentes modelos de negócio e os impactos na gestão empresarial In: BÜHLER, Eve Anne; GUIBERT, Martine; OLIVEIRA, Valter Lúcio de (Org.). Agriculturas empresariais e espaços rurais na globalização. Porto Alegre: Editora UFRGS, 2016. p. 193-216.

SCHERER-WARREN, Ilse. Redes e movimentos sociais: projetando o futuro. Revista Brasileira de Sociologia, v. 1, ano 1, p. 187-218, 2013. Disponível em: <http://dx.doi.org/10.20336/rbs.29>. Acesso em: 5 nov. 2017.

SILVEIRA, Rogério Leandro Lima et al. A sociedade civil e o planejamento regional no RS: uma análise qualitativa a partir dos Coredes. Revista Desenvolvimento Regional em Debate, v. 5, n. 2, p. 71-85, jun./dez. 2015.

Submetido em: 21/12/2017

Aceito em: 27/07/2018 


\title{
PROJECT PLANNING, MANAGEMENT AND EXECUTION: AN ARENA OF CONFLICTS BETWEEN ACTOR'S NETWORKS
}

\begin{abstract}
The papers intends to reflext on the relation between the actor's organization in networks and the disputes around the planning, management and execution of projects ths show conflicts in the territorial scope. Using as a base the theoretical analysis and examination onf bibliography, this text exposes some theoretical discussions about the network's notion, and then call attention to the importance of understanding the conflicts that arise surrounding the planning, management and execution of projets, emphasizing the actor's organizations in networks in the disputes, the social-environmental conflitct associated with the implementation of "big projects" and, finally, the tensions between projects among the local actors themselves that Express in spaces of participation instituted to management that some projects territories' modalities. From this argumentative route, it's suggested that the conflicts are constitutives of the planning, management and execution projets' process, not infrequently, actors not only organize themselves into networks establisshing alliances with other actors to disputes about project's conceptions, but also tho flight against, to prevent, to bar, to modify projects that are imposed by other networks abaut their territories and life's ways.
\end{abstract}

Keywords: Projects. Networks. Actors. Conflicts. Territory. 